\title{
Analysis of Stress Contributing Factors in Work Organizations in Public Institutions of Higher Learning
}

\section{Analisis Faktor Penyumbang Stres dalam Organisasi Kerja di Intitut Pengajian Tinggi Awam}

\author{
Zahrul Akmal Damin ${ }^{1 *}$, Khairunesa Isa ${ }^{1}$, Lutfan Jaes ${ }^{1}$, Zulida Abdul Kadir ${ }^{2}$, \\ Abdul Halim Abdul Rahman ${ }^{3}$
}

${ }^{1}$ Centre for General Studies and Cocurricular,

Universiti Tun Hussein Onn Malaysia, 86400 Parit Raja, Batu Pahat, Johor, MALAYSIA

${ }^{2}$ Centre for Language Studies,

Universiti Tun Hussein Onn Malaysia, 86400 Parit Raja, Batu Pahat, Johor, MALAYSIA

${ }^{3}$ Registrar Office,

Universiti Tun Hussein Onn Malaysia, 86400 Parit Raja, Batu Pahat, Johor, MALAYSIA

*Corresponding Author

DOI: https://doi.org/10.30880/jstard.2020.02.03.002

Received 30 September 2020; Accepted 30 November 2020; Available online 31 December 2020

\begin{abstract}
Stress is a condition that refers to the restless, anxious and tense situation a person faces due to stress or burden. This phenomenon of stress is increasingly serious in life including work organization. The problem of stress is increasingly focused because it can have negative implications for the organization such as decreased work productivity and high turnover rates as well as increasing the risk of accidents at work. Therefore, this paper aims to identify the factors that contribute to stress among staff in one of the Public Institutes of Higher Learning. The method used to achieve the objectives of this study is based on a quantitative approach by using simple random sampling techniques. A total of 535 respondents gave feedback through the distribution of questionnaires distributed. However, in the context of writing this article, only Part C involves open-ended questions regarding stress factors analyzed in a descriptive manner that includes numerical frequency and percentage. The results of the study found that the contributors to stress among staff are due to factors (i) organization; 429 frequency or $87.73 \%$, (ii) individuals; 47 frequency or $9.61 \%$, and (iii) family; 13 frequency or $2.66 \%$. Matters related to stress are important to study because through the identification of factors contributing to stress among staff, then intervention measures can be designed to increase work motivation. By implementing such an approach, it is hoped that the work organization will continue to be competitive and have the strength to achieve the work targets that have been set.
\end{abstract}

Keywords: Work organization, stress contribution, staff, stress 
Abstract: Stres merupakan satu keadaan yang merujuk kepada situasi resah, cemas dan tegang yang dihadapi oleh seseorang disebabkan tekanan atau bebanan. Fenomena stres ini semakin serius berlaku dalam kehidupan termasuk organisasi kerja. Permasalahan stres semakin mendapat tumpuan kerana ia mampu mendatangkan implikasi negatif kepada organisasi seperti penurunan produktiviti kerja dan kadar turnover tinggi selain meningkatkan risiko kemalangan di tempat kerja. Oleh itu, kertas kerja ini bertujuan untuk mengenalpasti faktor yang menyumbang kepada stres dalam kalangan staf di salah sebuah Institut Pengajian Tinggi Awam. Metode yang digunapakai bagi mencapai objektif kajian ini adalah berasaskan pendekatan kuantitatif dengan menggunakan teknik persampelan rawak mudah. Seramai 535 orang responden telah memberi maklumbalas menerusi pengedaran borang soal selidik yang diedarkan. Namun dalam konteks penulisan artikel ini, hanya Bahagian C sahaja yang melibatkan soalan open-ended berhubung faktor stres dianalisis secara diskriptif mudah merangkumi numberikal frekuensi dan peratusan. Hasil kajian menemukan bahawa penyumbang kepada stress dalam kalangan staf adalah disebabkan oleh faktor (i) organisasi; 429 frekuensi atau 87.73\%, (ii) individu; 47 frekuensi atau 9.61\%, dan (iii) keluarga; 13 frekuensi atau $2.66 \%$. Hal berhubung stres ini penting untuk diteliti kerana menerusi pengenalpastian faktor penyumbang kepada stres dalam kalangan staf maka langkah-langkah intervensi boleh dirangka bagi meningkatkan semula motivasi kerja. Dengan melaksanakan pendekatan tersebut diharapkan organisasi kerja terus mempunyai daya saing dan memiliki kekuatan untuk mencapai sasaran kerja yang telah ditetapkan.

Kata Kunci: Organisasi kerja, penyumbang stres, staf, stres

\section{Pengenalan}

Organisasi pada hari ini amat menekankan kepada kemampuan bersaing dalam mencapai matlamat yang ditetapkan. Dalam hal ini ia telah mempengaruhi cara individu untuk bekerja bagi memastikan matlamat organisasi dapat dicapai. Bagi tujuan tersebut, penetapan matlamat seperti Key Performance Indicator (KPI) mula dirangka dan disusun sebagai langkah strategik untuk mencapai matlamat akhir bagi kebanyakan organisasi. Berdasarkan penetapan KPI, organisasi mengharapkan output yang dihasilkan oleh pekerja lebih tinggi daripada sebelumnya. Akibatnya pekerja tidak akan merasa gembira untuk elakukan kerja kerana mereka terpaksa menukar rutin harian kerja mereka kepada rutin yang lebih kompleks dan mencabar (Wesarat, Sharif dan Abdul Majid, 2014). Dalam konteks organisasi yang berorientasikan perkhidmatan seperti Institut Pengajian Tinggi Awam (IPTA), penetapan KPI merupakan asas utama dalam usaha mencapai matlamat organisasi dan pada masa yang sama memastikan prestasi organisasi meningkat. Selain daripada perkhidmatan yang disampaikan oleh bahagian pentadbiran, penetapan KPI di IPTA juga merujuk kepada tujuh bidang utama yang dilakukan oleh pensyarah iaitu pengajaran, penulisan, penerbitan, penyelidikan, perundingan dan khidmat masyarakat. Semua indikator ini diukur dari segi pencapaian dan kualiti perkhidmatan serta diiktiraf dalam pelbagai bentuk pengiktirafan seperti MYRa dan QS rating. Mendepani cabaran untuk mencapai semua KPI yang ditetapkan, tidak dinafikan terdapat staf organisasi yang cenderung terdedah kepada perasaan tidak gembira semasa bekerja. Keadaan ini akhirnya menyebabkan berlaku ketidakseimbangan antara memenuhi tuntutan antara kerja dan keluarga (Rashid et al., 2012).

\section{Sorotan Karya}

Stres merupakan satu keadaan yang merujuk kepada situasi resah, cemas dan tegang yang dihadapi oleh seseorang disebabkan tekanan atau bebanan (Dewan Bahasa dan Pustaka, 2019). Menurut Lunberg dan Cooper (2011) stress mampu menyebabkan tahap kesejahteraan hidup individu dan prestasi organisasi terganggu. Oleh itu, stres dilihat sebagai satu masalah yang mengakibatkan seseorang individu berubah tingkahlakunya. Kajian Indeks Kebahagiaan Dunia 2018 meletakkan Malaysia sebagai negara ketiga paling bahagia, namun hakikatnya 30 peratus rakyat Malaysia menderita dengan masalah kesihatan mental disebabkan stres. Arumugam (2016) menjelaskan bahawa tiga daripada setiap orang dewasa di Malaysia berhadapan dengan penyakit mental disebabkan oleh pelbagai keadaan dan kebanyakannya disebabkan oleh stres dan berasa tidak bahagia dalam kehidupan. Sementara itu, kajian Morbiditi Kesihatan Kebangsaan (Kosmo Online, 2018) pula menyatakan setiap tiga orang dalam sepuluh orang dewasa berusia lebih 16 tahun menderita pelbagai isu kesihatan mental yang berpunca dari pelbagai sebab seperti stres, kecelaruan fikiran, kemurungan, skizofrenia dan konflik. Dalam dunia perkhidmatan pendidikan, ahli akademik dan bukan akademik turut terdedah dengan keadaan stres di tempat kerja. Kajian ke atas pensyarah Institut Perguruan Malaysia (IPGM) pada tahun 2010 mendapati golongan ini mengalami ketidak aturan dalam kehidupan apabila status maktab perguruan ditukar kepada institut perguruan yang memperlihatkan perubahan drastik dari segi beban tugas, skop tugas dan rutin harian. Pada tahun 2016, seorang pensyarah di Universiti Teknologi MARA (UiTM) Shah Alam dijumpai meninggal dunia di pejabatnya pada waktu bekerja dan siasatan mendapati pensyarah berkenaan terkena serangan jantung. Manakala data daripada Pejabat Pendaftar Universiti Tun Hussein Onn Malaysia (UTHM) menunjukkan keadaan seperti kekerapan mengambil cuti sakit, kos perbelanjaan perubatan yang tinggi, kerap hadir lewat ke pejabat, ponteng kerja, skizofrenia, mengambil cuti rehat tahunan yang berlebihan dan pertambahan bilangan kes yang dirujuk 
ke pusat kaunseling boleh dilihat antara simptom terdapat staf UTHM yang sedang berhadapan dengan masalah stress. Maka stres telah menimbulkan permasalahan dan hal ini telah menerbitkan tanda soal iaitu apakah faktor yang menyebabkan stres? Oleh itu, kertas kerja ini bertujuan untuk mengenalpasti faktor yang menyumbang kepada stres dalam kalangan staf di salah sebuah IPTA.

\section{Model Stres}

Stres dilihat sebagai satu proses yang mempunyai punca dan akibat sebagaimana Rajah 1. Menurut Robbins dan Judge (2005), terdapat tiga faktor yang berpotensi menjadi penyumbang stres dalam kalangan individu di tempat kerja iaitu faktor persekitaran, organisasi dan personal. Ketidakstabilan ekonomi dan politik serta perubahan teknologi merupakan antara elemen dalam faktor persekitaran yang berpotensi menyumbang kepada stres. Ketidakstabilan ekonomi dan politik yang berlaku akan memberi kesan kepada pengoperasian serta prestasi organisasi. Perubahan teknologi juga dilihat menyebabkan pekerja perlu menguasai kemahiran teknologi sebanyak mungkin walaupun berhadapan dengan kesukaran berbuat demikian. Dalam konteks faktor organisasi pula, permintaan terhadap tugas, peranan dan interpersonal pekerja dilihat lebih cenderung menyumbang kepada tahap stres di organisasi. Kegagalan pekerja memenuhi tuntutan dan permintaan majikan terhadap tugasan yang diberikan akan menyebabkan pekerja mengalami stres. Selain itu, permintaan personal pekerja yang tidak selari dengan pengurusan dan pentadbiran di organisasi juga akan menyebabkan pekerja menghadapi tekanan. Terakhir iaitu faktor personal dan tiga elemen yang paling kuat mempengaruhi stres adalah masalah keluarga, masalah ekonomi dan personaliti pekerja. Keluarga merupakan elemen paling rapat dalam kehidupan individu. Pekerja memerlukan ahli keluarga untuk berkongsi jika menghadapi masalah di tempat kerja dan begitu juga sebaliknya. Namun, sekiranya individu menghadapi masalah keluarga sedikit sebanyak ia akan mempengaruhi tahap emosi dan pemikiran pekerja di tempat kerja.

\section{A Model of Stress}

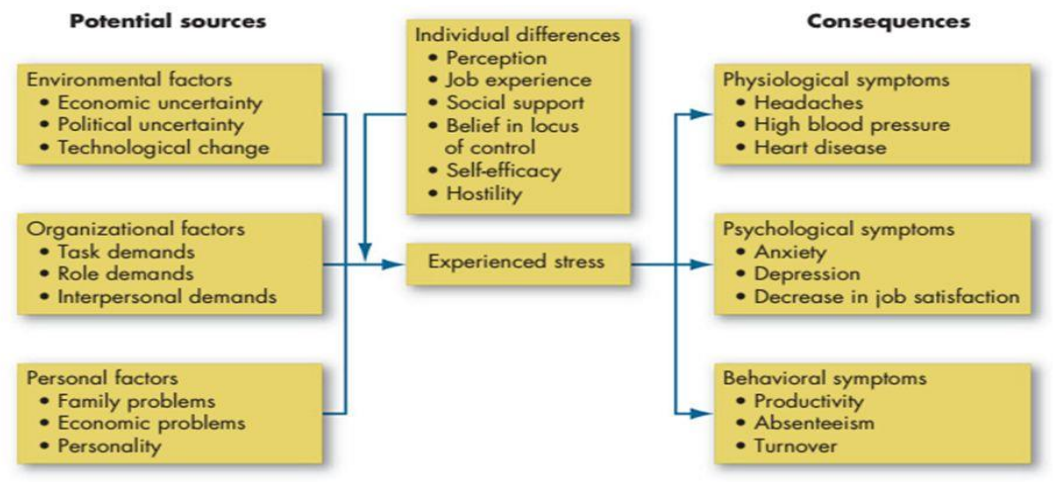

Rajah 1 - Model Stres

\section{Metodologi}

\section{Kaedah Penyelidikan}

Kajian ini merupakan satu kajian tinjauan berbentuk deskriptif. Kajian tinjauan dilihat berupaya mendapatkan data secara terus daripada responden kajian dan pada masa yang sama mampu tentang ankubah-angkubah yang wujud dalam situasi yang dikaji. Hal ini kerana menurut Fink (1995), tinjauan adalah cara maklumat untuk dihurai, dibanding, diramal dan dinilai berdasarkan maklum balas responden. Sementara itu Ary, Jacobs dan Sorensen (2010) berpandangan bahawa penggunaan kaedah tinjauan memberi kelebihan kerana ia melibatkan responden yang lebih ramai, luas dan menyeluruh. Kaedah ini dipilih dalam kajian ini adalah perolehan maklumat daripada pengutipan data dapat digeneralisasikan bagi mewakili kelompok yang lebih besar.

\section{Persampelan Kajian}

Populasi kajian ini adalah staf di Universiti A yang terdiri daripada staf akademik dan staf pentadbiran. Staf akademik bermula dari Gred 41 hingga Jusa A manakala staf pentadbiran merangkumi di peringkat Pengurusan dan Operasi (Kumpulan A dan B), Sokongan 1 (Kumpulan C) serta Sokongan 2 (Kumpulan D). Data daripada Pejabat Pendaftar Universiti A menunjukkan populasi staf Universiti A adalah seramai 2,338 orang dan daripada jumlah 
tersebut seramai 535 orang telah dipilih menjadi responden melalui kaedah persampelan rawak mudah. Menurut Krejcie dan Morgan (1970), saiz sampel bagi populasi 2,200 adalah sebanyak 327. Oleh itu, kajian ini telah mendapat kadar pulangan melebihi dari 100 peratus dari edaran yang dibuat. Namun demikian, kajian ini tidak mengasingkan antara populasi staf akademik dan staf pentadbiran dalam kaedah persampelan.

\section{Instrumentasi Kajian}

Instrumen yang digunakan dalam kajian ini untuk pengumpulan data pembolehubah adalah dengan menggunakan borang soal selidik. Terdapat empat bahagian dalam borang soal selidik ini iaitu Bahagian A dan Bahagian B iaitu bagi soalan berbentuk tertutup manakala Bahagian C dan D pula bagi soalan berbentuk terbuka sebagaimana Jadual 1.

\section{Jadual 1 - Empat Bahagian dalam Borang Soal Selidik}

\begin{tabular}{lll}
\hline Bahagian & Bentuk & \multicolumn{1}{c}{ Dimensi } \\
\hline Bahagian A & Tertutup & Demografi Responden \\
Bahagian B & Tertutup & Faktor Penyumbang Kebahagian \\
Bahagian C & Terbuka & Faktor Penyumbang Stres \\
Bahagian D & Terbuka & Faktor Penyumbang Kebahagian \\
\hline
\end{tabular}

\section{Prosedur Kajian}

Sebanyak 500 set borang soal selidik yang disediakan telah diedarkan kepada responden menerusi kotak surat (pigeon hole). Borang yang sudah siap dijawab dalam tempoh masa empat hari bekerja perlu dipulangkan semula kepada Pusat Tanggungjawab masing-masing. Walau bagaimanapun kadar pulangan semula borang soal selidik mencapai bilangan 135 set sahaja. Disebabkan hal ini, langkah inisiatif telah diambil untuk membuat edaran borang soal selidik melalui e-mel kepada staf. Sebanyak tiga kali edaran e-mel telah dibuat untuk mendapatkan jumlah bilangan soal selidik yang mencukupi. Hasilnya 400 set borang soal selidik telah berjaya diperoleh menerusi hebahan emel dan jumlah keseluruhan borang yang terkumpul adalah sebanyak 535 set.

\section{Analisis Data}

Borang soal selidik yang dihasilkan mempunyai empat bahagian iaitu A, B, C dan D. Oleh itu, analisa data berdasarkan borang soal selidik hanya dilakukan dengan melibatkan Bahagian $\mathrm{C}$ sahaja disebabkan ia selari dengan tajuk dan objektif kajian yang ditetapkan dalam kertas kerja ini. Data yang diperolehi dalam Bahagian $\mathrm{C}$ dianalisa dalam bentuk deskriptif mudah. Data yang diperolehi terlebih dahulu dipindah ke fail MS Word 2013 seterusnya dianalisa pada peringkat kata dan frasa seperti yang dicadangkan oleh Berg (2007). Setiap data yang diperolehi kemudiannya dikelompokkan berdasarkan tema dan subtema yang dibina berasaskan perbincangan model kebahagian hidup. Hasil daripada pengkelompokan tema dan subtema ini membolehkan pengiraan ke atas jumlah kekerapan data mentah dibuat seterusnya menyusun tema dan subtema mengikut bilangan yang tertinggi hingga ke peringkat yang rendah serta diberikan peratusan. Akhirnya, dapatan data yang dianalisa dilakarkan dengan menggunakan kerangka persembahan seperti saranan Weiss, Smith dan Theeboom (1996) serta Zahrul Akmal (2016).

\section{Perbincangan}

\begin{tabular}{llc}
\hline \multicolumn{1}{c}{ DATA MENTAH } & SUBTEMA & TEMA \\
\hline Faktor kewangan peribadi (15) & Masalah Personal (23) \\
Masalah kesihatan staf (4) & \\
Masalah peribadi (3) & \\
Kawalan emosi tidak baik (1) & \\
\hline Tidak menghargai sumbangan kerja (3) & \\
Staf kurang hormat (3) & \\
Tiada pengiktirafan APC (2) & \\
Memandang rendah (2) & Tiada Penghargaan \\
APC tidak berdasarkan merit, berdasarkan giliran (1) & Personal (17) \\
Tidak menghormati idea staf lain (1) & \\
Diskriminasi yang terlindung (1) & \\
Pendapat kurang didengari (1) & \\
Dinafikan hak (1) & \\
Ditindas (1) & \\
Pengurusan universiti ada favouratisme dalam memberi & \\
$\quad$ penghargaan (1) & \\
\hline
\end{tabular}




\begin{tabular}{ll}
\hline Kos sara hidup meningkat (2) & Ekonomi Personal (2) \\
\hline Kurang kebebasan untuk menggunakan kreativiti (1) & Suasana Pekerjaan \\
Multi-tasking, tidak ada fokus (1) & Personal (2) \\
\hline $\begin{array}{l}\text { Kurang motivasi kerja (1) } \\
\text { Tiada minat (1) }\end{array}$ & Galakan Personal (2) \\
\hline Kurang mendekatkan diri kepada Allah (1) & Kepercayaan Personal (1) \\
\hline
\end{tabular}

\section{Rajah 2 - Data-data Mentah Berhubung Faktor Stres Mengikut Tema Individu}

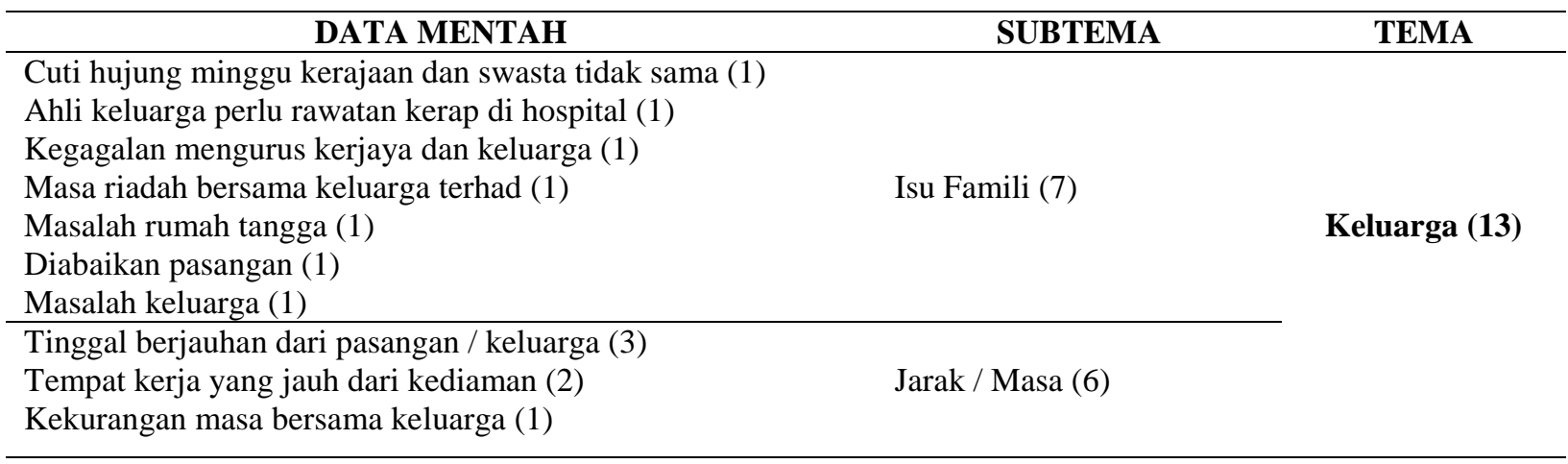

Rajah 3 - Data-data Mentah Berhubung Faktor Stres Mengikut Tema Keluarga

\begin{tabular}{l}
\multicolumn{1}{c}{ Data Mentah } \\
\hline Beban tugas yang berlebihan (31) \\
Kerja di luar bidang tugas (8) \\
Tekanan daripada pegawai atasan (6) \\
Workload tidak bertepatan dengan gred staf (4) \\
Kerja perlu disegerakan (3) \\
Buat kerja orang lain (3) \\
Banyak tugas pentadbiran, menjejaskan tugas hakiki \\
$\quad$ Pensyarah (2) \\
Pembahagian tugas tidak yang seimbang (2) \\
"7P" yang keterlaluan (2) \\
Kerja yang banyak (2) \\
Paksaan hadir kursus yang tiada output untuk pegawai (1) \\
Tugas perlu diselesaikan pada hujung minggu (1) \\
Perlu hadiri program di hujung minggu (1) \\
Pengurusan atasan terlalu mendesak (1) \\
Tekanan kerja yang mendesak (1) \\
Dekan tidak perlu tekan staf (1) \\
Tugas yang bertindan-tidan (1) \\
Tuntutan kerja yang tinggi (1) \\
Program yang banyak (1) \\
Jadual yang padat (1)
\end{tabular}




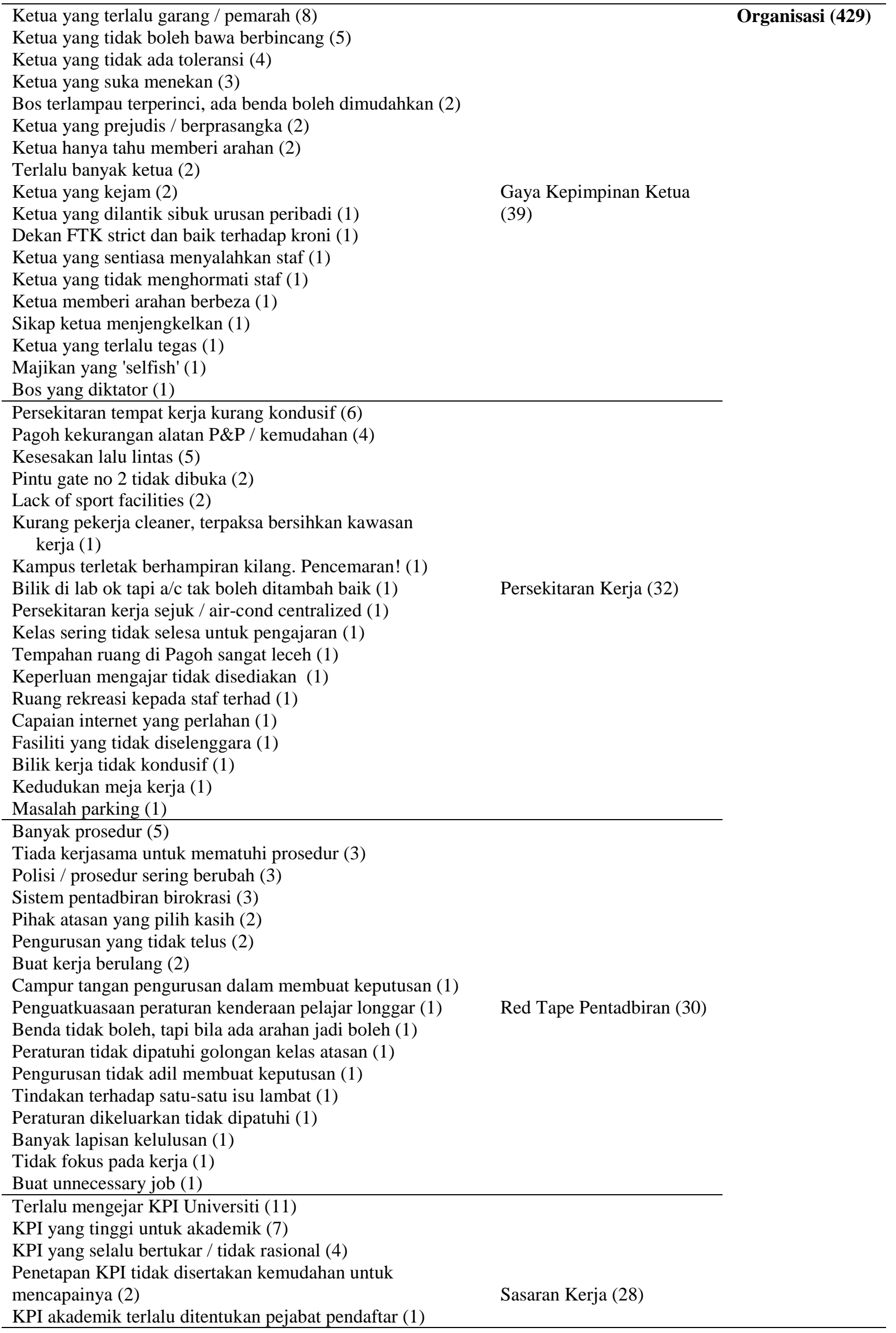




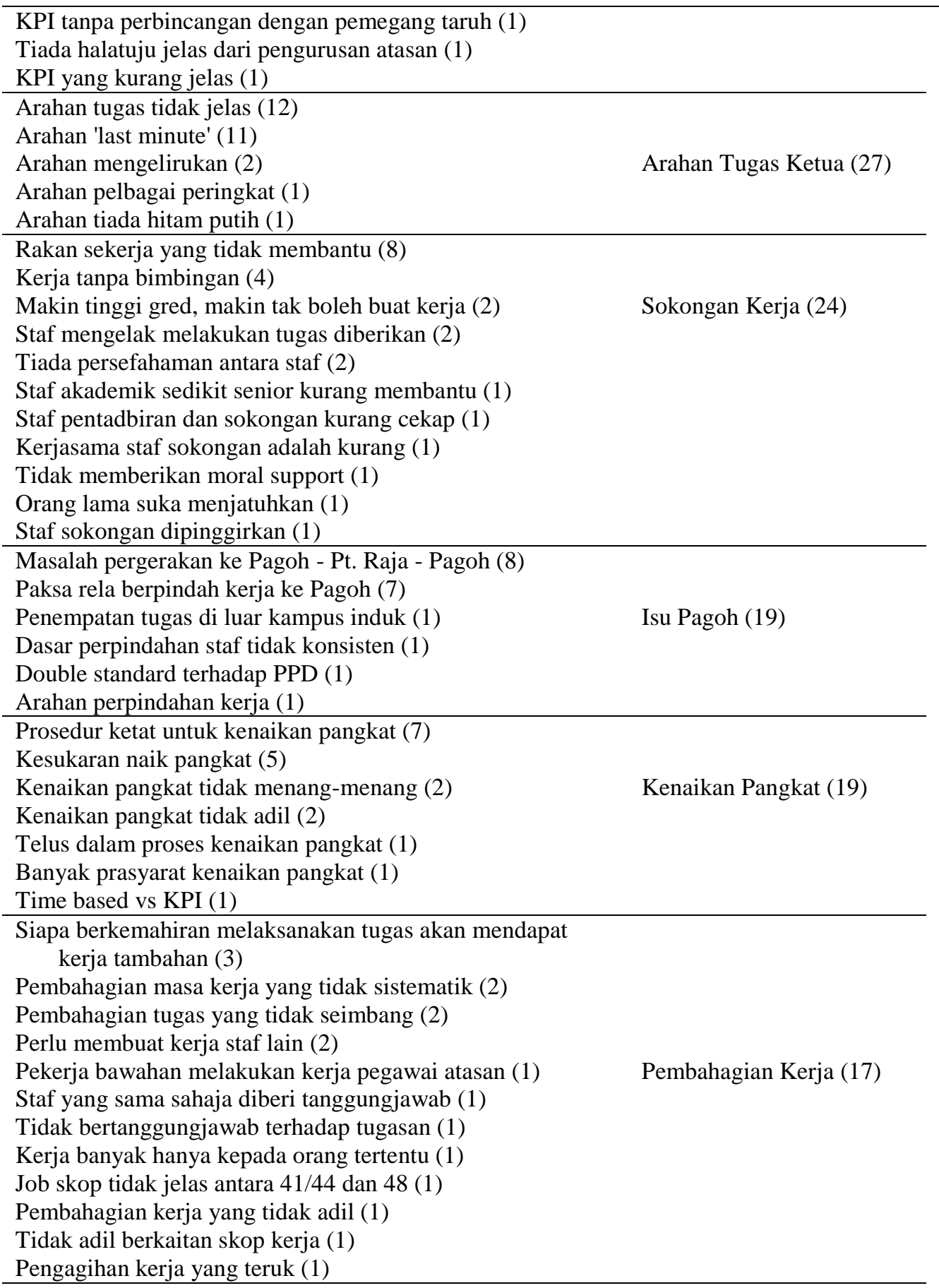

Kurang perhatian aspek kebajikan (7)

Pegawai penilai tidak peka situasi orang bawahan (1)

Pengurusan tidak endah tugas pembangunan diri (1)

Pihak atasan tidak mendengar pemasalahan (1)

Layan staf sebagai "rakan" bukan "pekerja" (1)

Kebajikan Pekerja (15)

Majikan kurang prihatin staf bawahan (1)

Hak bersuara kurang diberi perhatian (1)

Pentadbiran tiada perikemanusian (1)

Majikan yang tidak memahami (1)

Ketua tidak kompeten / tidak berkredibiliti (3)

Ketua yang rendah soft skills (3)

Pemilihan ketua jabatan tidak berdasarkan undi (1)

Kompetensi Kerja Ketua

Ketua tidak faham fungsi dan isu pentadbiran (1)

Pegawai yang belum memahami skop tugas (1)

Pelantikan pegawai yang tidak berkaliber (1) 


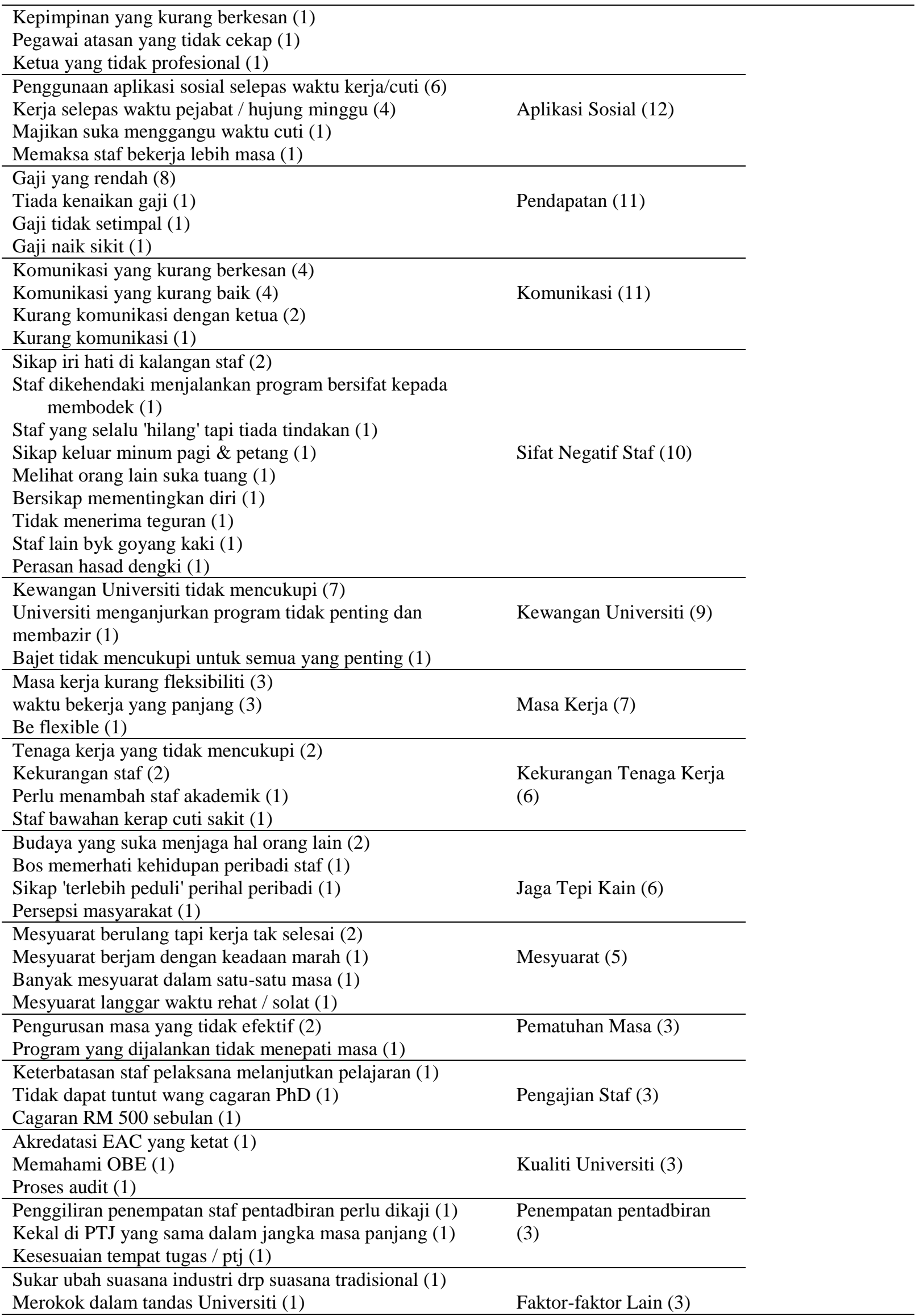

Rajah 4 - Data-data Mentah Berhubung Faktor Stres Mengikut Tema Organisasi 
Hasil daripada jawapan yang diberikan menerusi “open-ended question” Bahagian C di dalam borang soal selidik yang diedarkan kepada 535 orang responden, analisis mendapati bahawa terdapat tiga tema utama yang menjadi faktor penyumbang stres dalam kalangan staf di Universiti A. Tema-tema berkenaan dibangunkan berasaskan 429 item data mentah yang diteliti kekerapannya iaitu (i) Faktor Individu, sebanyak 47 kekerapan atau 9.61\%, (ii) Faktor Keluarga, sebanyak 13 kekerapan atau 2.66\%, dan (iii) Faktor Organisasi, sebanyak 429 kekerapan atau 87.73\% sebagaimana Rajah 2, Rajah 3, Rajah 4 serta Jadual 2.

\section{Jadual 2 - Faktor Stres Mengikut Tema, Kekerapan dan Peratus}

\begin{tabular}{llcr}
\hline No. & Tema & Kekerapan & Peratus \\
\hline 1 & Individu & 47 & 9.61 \\
2 & Keluarga & 13 & 2.66 \\
3 & Organisasi & 429 & 87.73 \\
& Total & 489 & 100.00 \\
\hline
\end{tabular}

Sumber: Responden

\section{Tema Pertama: Faktor Individu}

Dapatan analisis kajian menunjukkan bahawa "Faktor Individu" merupakan kategori tema yang mempunyai kekerapan frasa sokongan sebanyak 47 kekerapan. Tema ini adalah tema kedua utama dengan mewakili $9.61 \%$ daripada keseluruhan faktor penyumbang stress dalam kalangan staf di Universiti A. Daripada tema ini, terdapat enam subtema yang terbina di bawahnya iaitu (i) masalah personal, (ii) tiada penghargaan personal, (iii) ekonomi personal, (iv) suasana pekerjaan personal, (v) galakkan personal, dan (vi) kepercayaan personal sebagaimana Jadual 3.

\section{Jadual 3 - Faktor Stres Mengikut Subtema Individu Berdasarkan Kekerapan dan Peratus}

\begin{tabular}{llcl}
\hline No. & Subtema & Kekerapan & Peratus \\
\hline 1 & Masalah Personal & 23 & 4.70 \\
2 & Tiada Penghargaan Personal & 17 & 3.48 \\
3 & Ekonomi Personal & 2 & 0.41 \\
4 & Suasana Pekerjaan Personal & 2 & 0.41 \\
5 & Galakkan Personal & 2 & 0.41 \\
6 & Kepercayaan Personal & 1 & 0.20 \\
& Total & 47 & 9.61 \\
\hline
\end{tabular}

Sumber: Responden

Mohd Akmal Firdaus (2017) bersependapat bahawa masalah peribadi staf turut menjadi faktor penghalang kepada kecemerlangan organisasi. Dalam konteks di Universiti A, masalah peribadi ini dikaitkan dengan masalah kewangan, kesihatan dan sikap yang dihadapi oleh staf. Sementara itu dalam meningkatkan kecemerlangan kerja, Zarina, Nor Aishah dan Muhammad (2018) menyarankan agar pengiktirafan serta penghargaan diberi keutamaan oleh organisasi bagi mengelakkan motivasi kerja staf jatuh. Hal ini kerana terdapat staf di Universiti A ada yang berpandangan bahawa sumbangan kerja mereka adalah tidak dihargai selain isu pihak atasan yang kurang hormat dan memandang rendah staf bawahan mereka. Antara lain perbincangan asas kepada faktor stres ini tidak dapat lari daripada persoalan ekonomi.

Nuraini (2015) dalam kajiannya menemukan bahawa stres yang dihadapi oleh pekerja di Semenanjung Malaysia turut disumbangkan oleh peningkatan kos sara hidup. Perkara ini turut menjadi dilema kepada staf di Universiti A yang melihat kos sara hidup yang meningkat telah mendorong kepada stres dalam pekerjaan mereka. Dalam pada itu, Abdul Said (2017) berpandangan bahawa suasana pekerjaan turut perlu ditingkatkan agar warga pendidik tidak merasa stres. Situasi di Universiti A memperlihatkan wujudnya sekatan terhadap penggunaan daya kreativiti oleh staf dalam perlaksanaan tugas. Lebih merisaukan bahawa kehendak kepada multi-tasking dalam pekerjaan telah menyebabkan staf kehilangan fokus. Walau bagaimanapun Chong, Muhammad Faizal dan Zuraidah (2018), melihat stres dalam pekerjaan pendidikan juga disumbangkan oleh tiada galakan atau bimbingan kerja. Senario ini amat menggusarkan kerana terdapat staf di Universiti A yang telah kehilangan motivasi kerja dan sekiranya langkah prevensi tidak diambil maka ia akan mengganggu kecemerlangan organisasi.

\section{Tema Kedua: Faktor Keluarga}

Dapatan analisis kajian menunjukkan bahawa "Faktor Keluarga" merupakan kategori tema yang mempunyai kekerapan frasa sokongan sebanyak 13 kekerapan. Tema ini adalah tema ketiga utama dengan mewakili $2.66 \%$ daripada keseluruhan faktor penyumbang stress dalam kalangan staf di Universiti A. Daripada tema ini, terdapat dua subtema yang terbina di bawahnya iaitu (i) isu famili, dan (ii) jarak / masa sebagaimana Jadual 4.

Jadual 4 - Faktor Stres Mengikut Subtema Keluarga Berdasarkan Kekerapan dan Peratus 


\begin{tabular}{llcl}
\hline No. & Subtema & Kekerapan & Peratus \\
\hline 1 & Isu Famili & 7 & 1.43 \\
2 & Jarak / Masa & 6 & 1.23 \\
& Total & 13 & 2.66 \\
\hline
\end{tabular}

Sumber: Responden

Berdasarkan kajian yang dilaksanakan oleh Nor Azimah (2016), isu campur tangan keluarga terhadap kerja berlaku apabila wujudnya tuntutan pemenuhan tanggungjawab keluarga dalam waktu kerja. Kes di Universiti A juga menunjukkan bahawa hal ini berlaku walaupun bilangannya kecil. Ia seperti menguruskan ahli keluarga yang mendapatkan rawatan di hospital dalam waktu kerja. Isu yang berbeza pula ditemukan oleh Sharifah Hayaati (2017) iaitu staf tidak meluangkan masa yang cukup bersama keluarga dan perkara ini turut berlaku di Universiti A apabila ada responden menyatakan masa riadah bersama keluarga adalah terhad. Hal ini terjadi rentetan staf terpaksa memperuntukan waktu kerja yang lebih walaupun sudah tamat waktu bekerja di pejabat. Tambahan daripada penemuan ini, responden di Universiti A turut berhadapan dengan isu tinggal berjauhan dengan pasangan serta keluarga. Kajian daripada Tengku Sarina Aini dan Fatimah Sahida (2018) telah menemukan bahawa warga pendidik yang hidup berjauhan daripada keluarga akan mengganggu perlaksanaan tanggungjawab di tempat kerja.

\section{Tema Ketiga: Faktor Organisasi}

Dapatan analisis kajian menunjukkan bahawa "Faktor Organisasi" merupakan kategori tema yang mempunyai kekerapan frasa sokongan tertinggi iaitu sebanyak 429 kekerapan. Tema ini adalah tema paling utama dengan mewakili 87.73\% daripada keseluruhan faktor penyumbang stress dalam kalangan staf di Universiti A. Daripada tema ini, terdapat 26 subtema yang terbina di bawahnya iaitu (i) tanggungan kerja, (ii) gaya kepimpinan ketua, (iii) persekitaran kerja, (iv) red tape pentadbiran, (v) sasaran kerja, (vi) arahan tugas ketua, (vii) sokongan kerja, (viii) isu Pagoh, (ix) kenaikan pangkat, (x) pembahagian kerja, (xi) kebajikan pekerja, (xii) kompetensi kerja ketua, (xiii) aplikasi sosial, (xiv) pendapatan, (xv) komunikasi, (xvi) sifat negatif staf, (xvii) kewangan universiti, (xviii) masa kerja, (xix) kekurangan tenaga kerja, (xx) jaga tepi kain, (xxi) mesyuarat, (xxii) pematuhan masa, (xxiii) pengajian staf, (xxiv) kualiti universiti, (xxv) penempatan pentadbiran, dan (xxvi) faktor-faktor lain sebagaimana Jadual 5.

Menurut Sarimah dan Faridatul Akmar (2010), tanggungan kerja yang tinggi di universiti dikhuatiri mendatangkan ketidakpuashatian bekerja. Dalam konteks di Universiti A, staf berhadapan dengan beban tugas yang berlebihan dan kerja di luar bidang tugas disamping menerima tekanan daripada pegawai atasan. Selain itu, beban kerja yang tidak bertepatan dengan gred staf dan melakukan kerja-kerja orang lain juga memberikan tekanan kepada staf di Universiti A. Perkara yang menakutkan dalam hal ini adalah apabila tekanan yang dihadapi menyebabkan staf tidak mampu berinteraksi secara baik apabila mereka dihubungi (Norzihan, Ferlis \& Beddu, 2008).

Staf di Universiti A pada masa yang sama turut berhadapan dengan situasi stres disebabkan gaya kepimpinan ketua yang tidak disenangi. Hal ini seperti ketua yang pemarah, ketua yang tidak boleh dibawa berbincang, ketua yang tiada toleransi dan ketua yang suka menekan. Kajian oleh Hairul Akmal (2014) mendapati seseorang ketua akan berurusan secara negatif terhadap stafnya sekira mereka dalam keadaan stres dan emosinya tidak terkawal. Oleh demikian Azman, Suhailah, Wan Abdullah dan Nordiana (2016) mencadangkan agar diuruskan dengan penuh kebijaksanaan oleh organisasi. Hal ini kerana dalam kes di Universiti A, stres yang dihadapi oleh ketua telah mendatangkan kesan yang negatif kepada staf apabila staf yang diselia juga menghadapi stres.

Jadual 5 - Faktor Stres Mengikut Subtema Organisasi Berdasarkan Kekerapan dan Peratus

\begin{tabular}{llcc}
\hline No. & Subtema & Kekerapan & Peratus \\
\hline 1 & Tanggungan Kerja & 74 & 15.13 \\
2 & Gaya Kepimpinan Ketua & 39 & 7.98 \\
3 & Persekitaran Kerja & 32 & 6.54 \\
4 & Red Tape Pentadbiran & 30 & 6.13 \\
5 & Sasaran Kerja & 28 & 5.73 \\
6 & Arahan Tugas Ketua & 27 & 5.52 \\
7 & Sokongan Kerja & 24 & 4.91 \\
8 & Isu Pagoh & 19 & 3.89 \\
9 & Kenaikan Pangkat & 19 & 3.89 \\
10 & Pembahagian Kerja & 17 & 3.48 \\
11 & Kebajikan Kerja & 15 & 3.07 \\
12 & Kompetensi Kerja Ketua & 13 & 2.66 \\
13 & Aplikasi Sosial & 12 & 2.46 \\
14 & Pendapatan & 11 & 2.25 \\
15 & Komunikasi & 11 & 2.25
\end{tabular}




\begin{tabular}{llrr}
16 & Sifat Negatif Staf & 10 & 2.04 \\
17 & Kewangan Universiti & 9 & 1.84 \\
18 & Masa Kerja & 7 & 1.43 \\
19 & Kekurangan Tenaga Kerja & 6 & 1.23 \\
20 & Jaga Tepi Kain & 6 & 1.23 \\
21 & Mesyuarat & 5 & 1.02 \\
22 & Pematuhan Masa & 3 & 0.61 \\
23 & Pengajian Staf & 3 & 0.61 \\
24 & Kualiti Universiti & 3 & 0.61 \\
& Total & 429 & 87.73 \\
\hline
\end{tabular}

Sumber: Responden

Antara lain, staf di Universiti A turut berhadapan dengan keadaan persekitaran kerja yang tidak optima dan ia telah menjadi faktor stres di tempat kerja. Hal ini seperti persekitaran tempat kerja yang kurang kondusif, kekurangan peralatan Pengajaran dan Pembelajaran (P\&P), kesesakan lalulintas, kurang pekerja pembersihan bangunan, pencemaran oleh asap kilang serta isu penyejuk hawa dingin. Zafir, Sheikh Muhamad Hizam dan Nur Sa'adah (2018) dalam kajiannya tidak menafikan faktor persekitaran boleh menyebabkan stres namun cabaran persekitaran perlu dikawal bagi membolehkan sesuatu pekerjaan dilaksanakan dengan berkesan.

Pada masa yang sama, staf di Universiti A juga berhadapan dengan kerenah red-tape dalam pentadbiran yang akhirnya telah menyebabkan stres. Dapatan telah menunjukkan staf terpaksa mengharungi banyak prosedur, perubahan prosedur yang kerap, pentadbiran yang birokrasi, pengulangan kerja dan hasilnya tiada kerjasama untuk membuat kerja mengikut prosedur ditetapkan. Ironinya, prosedur yang ditetapkan sewajarnya memudahkan kerja-kerja yang dibuat namun akhirnya ia telah meyukarkan perlaksanaan kerja. Natijah daripada perkara tersebut menurut Kamaazura, Ahmad Munir, Mohd Shaladdin, Azlinzuraini dan Ruzita (2015), pendekatan organisasi yang dirasakan baik ini telah menyebabkan organisasi menjadi kurang efisyen dan melambatkan pembuatan keputusan.

Sementara itu, sasaran kerja tahunan juga dikenalpasti berperanan sebagai faktor yang menyebabkan stres dalam kalangan staf di Universiti A. Menurut responden, mereka merasa stres apabila universiti terlalu mengejar KPI, penekanan KPI yang terlalu tinggi untuk kumpulan akademik, organisasi yang menetapkan KPI yang tidak rasional dan penetapan KPI yang tidak seiring dengan penyediaan kemudahan untuk mencapainya. Norzaini dan Faridah (2016) berpendapat, kebanyakan ahli kumpulan akademik beremosi dan mengalami stres yang tinggi dalam memenuhi KPI. Hal ini kerana mereka dipaksa untuk mencapai KPI yang telah ditetapkan dan tidak menghairankan sekiranya ada ahli akademik yang bersifat memberontak.

\section{Kesimpulan}

\section{Rumusan Kajian}

Dapatan untuk menjawab objektif kajian menemukan penyumbang kepada stres dalam kalangan staf di Universiti A adalah faktor organisasi (429 frekuensi atau 87.73\%) sebagai tema terpenting. Ia kemudiannya diikuti oleh tema kedua penting dalam penyumbang kepada stres iaitu faktor individu (47 frekuensi atau 9.61\%) dan diakhiri dengan faktor keluarga (13 frekuensi atau 2.66\%). Penemuan ini penting bagi membolehkan pihak pengurusan di Universiti A mengambil langkah penambahbaikan untuk meningkatkan motivasi kerja seterusnya mengekalkan momentum persaingan dalam kalangan organisasi IPTA.

\section{Limitasi Kajian}

Kajian yang dilaksanakan ini hanya menggunapakai reka bentuk tinjauan dalam kalangan staf di Universiti A. Kaedah menganalisa data pula melibatkan penelitian hanya kepada soalan terbuka pada Bahagian $\mathrm{C}$ borang soal selidik. Oleh itu, kajian lanjutan berhubung isu stres dalam kalangan staf di organisasi IPTA adalah disarankan dengan menggunakan rekabentuk Round Table Discussion (RTD) dan Focus Group Discussion (FGD). Hal ini disebabkan rekabentuk temubual ini mampu mengumpulkan data yang lebih mendalam.

\section{Implikasi Kajian}

Dapatan daripada kajian ini menyarankan agar tanggungan kerja oleh staf perlu dilihat semula terutama bebanan tugas yang berlebihan, kerja di luar bidang tugas serta tekanan daripada pegawai atasan. Selain itu, pihak pengurusan universiti juga perlu melihat semula gaya kepimpinan ketua agar kepimpinan yang diamalkan berbentuk mesra staf, bertoleren dan mempermudahkan kerja. Turut perlu ditekankan adalah persekitaran kerja yang kondusif perlu disediakan kepada setiap staf yang bekerja. Dalam hal ini, pihak pengurusan universiti bersama Pejabat Pedaftar harus memfokuskan kepada SKT yang telah dibangunkan dan wajar mengurangkan arahan bersifat politik bagi mengurangkan beban kerja berlebihan. Kepimpinan kanan universiti juga pada masa yang sama perlu diberi latihan khusus untuk memimpin organisasi dan adalah disarankan agar kursus ini perlu dikendalikan oleh konsortium luar bagi 
mempelbagaikan sudut pandangan. Langkah yang perlu diambil juga adalah dengan meningkatkan persekitaran kerja yang positif dan kondusif.

\section{Penghargaan}

Kajian ini dijalankan dengan sokongan peruntukkan daripada NSFC/UTHM, Projek (C072).

\section{Rujukan}

[1] Abdul Said Ambotang. (2017). Stres dalam kalangan warga pendidik. Diambil daripada http://eprints.ums.edu.my/5721/1/Stres\%20dalam\%20kalangan\%20warga\%20pendidik.pdf

[2] Ary, D., Jacobs, L. C., \& Sorensen, C. K. (2010). Introduction to research in education. Australia: Wadsworth Cengage Learning

[3] Azman Hassan, Suhailah Mohd Yatim, Wan Abdullah Wan Ahmad \& Nordiana Rosmin. (2016). Emotional intelligence in leadership as a stress-coping mechanism among teachers: A critical literature review. Kertas kerja dibentangkan di 6th International Conference on Global Social Entrepreneurship, Kota Bharu

[4] Berg, B. L. (2007). Qualitative research methods for the social sciences (Ed. ke-6). Boston: Allyn \& Bacon

[5] Chong Chee Keong, Muhammad Faizal A. Ghani \& Zuraidah Abdullah. (2018). Cabaran amalan komuniti pembelajaran dalam kalangan guru sekolah rendah berprestasi tinggi Malaysia. Jurnal Kurikulum \& Pengajaran Asia Pasifik, 6(3), 1-14

[6] Dewan Bahasa dan Pustaka. (2019). Stres. Diambil daripada http://prpm.dbp.gov.my/Cari1? keyword=stres.

[7] Fink, A. (1995). How to measure survey reliability and validity (Vol. 7). Thousand Oaks, CA: Sage Publications

[8] Hairul Akmal Mohd Halim. (2014). Stres sebagai moderator ke atas hubungan antara gaya kepimpinan ketua dengan tingkah laku buli (Disertasi Sarjana). Universiti Teknologi Malaysia, Skudai

[9] Kamaazura Abu Bakar, Ahmad Munir Mohd Salleh, Mohd Shaladdin Muda, Azlinzuraini Ahmad \& Ruzita Manshor. (2015). Challenge-stress and hindrance-stress in the Southeast Asian hotel sector. Journal of Indonesian Economy and Business, 30(2), 101-112

[10] Krejcie, R.V., \& Morgan, D.W. (1970). Determining Sample Size for Research Activities. Educational and Psychological Measurement, 30, 607-610

[11] Lundberg, U, \& Cooper, C.L., (2011). The science of Occupational Health: Stress, Psychobiology and the New World of Work. West Sussex: Wiley Blackwell

[12] Mohd Akmal Firdaus Mohamad Hamim. (2017). Kompetensi guru reka cipta dalam bidang elektrik di sekolah menengah harian di Johor (Disertasi Sarjana). Universiti Tun Hussein Onn Malaysia, Johor

[13] Nor Azimah Chew Abdullah. (2016). Konflik Kerja-Keluarga Dalam Kalangan Pensyarah: Satu Tinjauan. Sains Humanika, 8(4-2), 131-135

[14] Norzaini Azman \& Faridah Mydin Kutty. (2016). Imposing global university rankings on local academic culture. Dalam M. Yudkevich, P. G. Altbach \& L. E. Rumbley (Eds.), The global academic rankings game. New York: Routledge Taylor \& Francis Group

[15] Norzihan Ayub, Ferlis Bahari \& Beddu Salam Baco. (2008). Burnout dan komitmen terhadap organisasi di kalangan jururawat hospital. Jurnal Kemanusiaan, 12, 73-86

[16] Nuraini Abdullah. (2015). Pengurusan hutang dalam kalangan pekerja muda di zon tengah, Semenanjung Malaysia (Disertasi Sarjana). Universiti Putra Malaysia, Serdang

[17] Phathara on Wesarat, Mohmad Yazam Sharif \& Abdul Halim Abdul Majid. (2015). A conceptual framework of happiness at the workplace. Asian Social Science, 11(2), 78-88

[18] Robbins S. P, \& Judge, T. A. (2005). Organizational Behaviour. Boston: Pearson

[19] Sarimah Ismail \& Faridatul Akmar Talip. (2010). Kepuasan bekerja staf akademik Jabatan Pendidikan Teknikal dan Kejuruteraan, Fakulti Pendidikan, Universiti Teknologi Malaysia, Skudai. Skudai: Universiti Teknologi Malaysia

[20] Sharifah Hayaati Syed Ismail. (2017). Mengurus antara keluarga dan kerjaya organisasi: Analisis melalui pendekatan al-Tadayyun, al-Maqasid dan al-Wasatiyyah. Akademika, 87(3), 195-206

[21] Tengku Sarina Aini Tengku Kasim \& Fatimah Sahida AbduRajak. (2018). Pengalaman pengajaran guru novis Pendidikan Islam: Implikasi terhadap reka bentuk kurikulum latihan pendidikan guru. Jurnal Pendidikan Malaysia, 43(1), 59-66

[22] Weiss, M. R., Smith, A. L., \& Theeboom, M. (1996). That's what friends are for: Children's and teenagers' perception of peer relationships in the sport domain. Journal of Sport \& Exercise Psychology, 18, 347-379

[23] Zafir Mohd Makhbul, Sheikh Muhamad Hizam Sheikh Khairuddin \& Nur Sa'adah Muhamad. (2018). Hubungan stres pekerjaan dan produktiviti: Tinjauan terhadap pentadbir fakulti universiti penyelidikan. Journal of Social Sciences and Humanities, 15(5), 168-180

[24] Zahrul Akmal Damin. (2016). Dasar kerajaan dan isu sekuriti makanan di Malaysia: Kajian analisis dokumen dan temubual (Tesis doktoral). Universiti Utara Malaysia, Kedah 
[25] Zarina Kassim, Nor Aishah Buang \& Muhammad Hussin. (2018). Tahap Sokongan Majikan terhadap Tahap Keterlibatan Program Lifelong Learning (LLL) Pekerja Perusahaan Kecil dan Sederhana (PKS). Jurnal Pendidikan Malaysia, 43(3), 117-121 